\title{
Numerical Simulation of Conical Pick Cutting Arc Rock Plate Fracture Based on ANSYS/LS-DYNA
}

\author{
Zhiwen Wang $\mathbb{D},{ }^{1}$ Qingliang Zeng $\mathbb{D},{ }^{1,2}$ Zhenguo Lu $\left(\mathbb{D},{ }^{3}\right.$ Lirong Wan, ${ }^{1}$ Xin Zhang, \\ and Guanshun Gao ${ }^{1}$ \\ ${ }^{1}$ College of Mechanical and Electronic Engineering, Shandong University of Science and Technology, Qingdao 266590, China \\ ${ }^{2}$ College of Information Science and Engineering, Shandong Normal University, Jinan 250358, China \\ ${ }^{3}$ College of Transportation, Shandong University of Science and Technology, Qingdao 266590, China
}

Correspondence should be addressed to Qingliang Zeng; qlzeng@sdust.edu.cn

Received 5 July 2020; Revised 7 December 2020; Accepted 14 December 2020; Published 23 December 2020

Academic Editor: Yue Hou

Copyright $(92020$ Zhiwen Wang et al. This is an open access article distributed under the Creative Commons Attribution License, which permits unrestricted use, distribution, and reproduction in any medium, provided the original work is properly cited.

The new method of rock breaking based on the combination of circular sawblade and conical pick was proposed to improve the effectiveness of hard rock breaking. The numerical simulation method was applied to research the conical pick cutting arc rock plate by ANSYS/LS-DYNA. The conical pick cutting arc rock plate numerical simulation model was established to research the influence of arc rock plate structural parameters and cutting parameters on cracks formation and propagation of the arc rock plate and the cutting force in the process of conical pick cutting arc rock plate. The amount of cracks is positively correlated with arc rock plate thickness, the cutting speed, and distance of cutting point to arc rock plate central axis and negatively correlated with the cutting angle. The mean peak cutting force is positively correlated with the thickness of arc rock plate and the distance of cutting point to arc rock plate central axis; however, it is negatively correlated with the arc rock plate height and width and cutting angle of conical pick. The simulation results can be used to predict the conical pick work performance with various cutting parameters and structural parameters.

\section{Introduction}

The conical pick is widely used in mining and it is an important part of mining machine [1]. Many scholars have produced theoretical and experimental investigations and numerical simulation to research the rock cutting. The theories can help us to comprehend the process of rock cutting; therefore, some experts have researched the rock cutting with theoretical methods. Goktan [2], Nishimatsu [3], and Evans [4] proposed the cutting force theories of point attack pick. Hult [5] and Chranowski [6] proposed the theory of damage mechanics and fracture mechanics to handle the issue of concrete failure. And some scholars have taken tests to research the rock cutting. Liu et al. [7] presented a kind of rock drilling method and conducted tests to research its cutting performance. Too many tests about the process of chip formation were to be provided by Che et al. [8]. Yin et al. [9] explored the effect of confining pressure stress on rock fragmentation by indentation test. More scholars have investigated the mechanism of rock fragmentation by the numerical simulation in the process of conical pick cutting rock. Huang et al. [10] and Jiang et al. [11] applied the finite element method to simulate rock cutting process, which pointed out the fact that the theoretical and experimental studies are closely related. Lu et al. [12] established the numerical simulation model of conical pick cutting rock, researching the influence of cutting parameters on cutting force and fragments. The rock breaking process was simulated by Menezes [13] with different rock conditions using the finite element method. Li et al. $[14,15]$ used the finite element method to research the process of rock cutting. Zeng et al. [16] researched the damage of coal and rock based on LS-DYNA.

In order to improve the cutting effective, too many new methods have been proposed. Based on the SPH/FEA method, Jiang et al. [17] studied the water-jet forming the 
rock fragments. Tang et al. [18] proposed a new method to improve the efficiency of mining, utilizing the method of abrasive water-jet in combination with rock drilling. The free-face-assisted rock breaking method was researched by Geng et al. [19]. Though the theories can help us to comprehend the process of rock cutting, they are not accurate and effective to establish the cutting force models; owing to the anisotropic and heterogeneous characteristics of the natural stone [20], the experimental study is a kind of effective and reliable method but costs more time and money [21]. The numerical simulation method is suitable for the conical pick cutting arc rock plate in this paper.

With the development of fully mechanized mining and fully mechanized excavation technology, the speed of coal mining has increased significantly. However, the driving speed of the rock roadway and semicoal rock roadway lags behind the mining speed of coal obviously, which is restricting the mining speed of coal and affects the safety of coal mining. Due to the limitation of the tool material, tool wear seriously and rock breaking efficiency are low while breaking the hard rock, and too many researchers studied that $[22,23]$. In order to overcome the problem that the wear of pick seriously restricts the driving speed of hard rock, method of rock breaking by combination of diamond sawblade and conical pick was put forward to improve the driving ability of driving equipment, as displayed in Figure 1(a). The diamond sawblades cut hard rock with a certain cutting depth to form sawn joints and the arc rock plates; then the conical picks cut the arc rock plate which can improve rock breaking efficiency, as shown in Figures 1(b) and $1(\mathrm{c})$.

\section{Methodology}

2.1. Establishment of the Numerical Simulation Model. The numerical simulation model of the conical pick-arc rock plate with ANSYS/LS-DYNA is established, as shown in Figure 2. The arc rock plate model is mainly composed of two parts including the middle part arc rock plate and the rock base. The impact angle of conical pick is $57^{\circ}$ and the tip angle is $80^{\circ}$, denoted as $\alpha$ and $\beta$, respectively. $l_{x}, l_{y}$, and $l_{z}$ in Figure 2 are the thickness, width, and height of the arc rock plate, respectively. In order to describe the influence of the cutting point to arc rock plate central axis distance on the cutting performance of the conical pick, the distance of cutting point to arc rock plate central axis is defined as $l_{d} / l_{y}$; $l_{d}$ is the cutting point to the arc rock plate edge. The rock material model is defined as JOHNSON_HOLMQUIST_CONCRETE (JHC), and the key parameters of rock material model are shown in Table 1. Mesh generation of arc rock plate and conical pick was carried out using the hexahedral element. The contact type between the conical pick and arc rock plate model was defined as AUTOMATIC_GENERALE and ERODING_SURFACE_TO_SURFACE. Full integration was adopted to avoid the influence of hourglass energy and mesh distortion on calculation accuracy. Applying constraints to the finite element model, the full constraint was added on the underlying surface, the $y$-axis direction constraint was added to the front and back surfaces of base rock, and the $x$-axis direction constraint was applied to the left and right surfaces. The displacement constraint in $y$ - and $z$-axes directions and full rotation constraint were added to the conical pick. The nonboundary reflection condition was added to arc rock plate surface which is uncutting and the mass scaling was not used to improve the accurate simulation of the conical pick cutting arc rock plate.

The key parameters of four kinds rocks which are sandstone-1, sandstone-2, sandstone-3, and limestone, as shown in Table 2, were selected as the rock material in the numerical simulation.

In order to study the effect of arc rock plate structural parameters and cutting parameters on cutting performance accurately, the numerical simulation model was established with various cutting parameters and structural parameters of arc rock plate.

\subsection{Rock Constitutive Model. The JOHSON_HOLM-} QUIST_CONCRETE (JHC) was selected for rock material, which is suitable for rock and concrete, etc. The equivalent yield strength is a function of pressure, strain rate, and damage, while the pressure is a function of volume strain, and damage accumulation is a function of plastic volume strain and equivalent plastic strain.

The following formula shows that the strength normalized the equivalent stress expression of JHC:

$$
\sigma^{*}=\left[A(1-D)+B P^{* N}\right]\left(1+C \ln \dot{\varepsilon}^{*}\right)
$$

in which $\sigma^{*}$ is the dimensionless equivalent stress $\sigma^{*}=\sigma / \dot{f}_{c}$, $\sigma$ is the actual equivalent stress, $\dot{f}_{c}$ is the quasistatic yield strength, and $S_{\mathrm{MAX}}$ is the maximum value of $\sigma$ normalized dimensionless equivalent stress, $\sigma^{*} \leq S_{\mathrm{MAX}} . P^{*}$ is the dimensionless pressure, $P^{*}=P / \dot{f}_{c}, P$ is the actual pressure, $\dot{\varepsilon}^{*}$ is the dimensionless strain rate, $\dot{\varepsilon}^{*}=\dot{\varepsilon} / \dot{\varepsilon}_{0}, \dot{\varepsilon}$ is the strain rate, and $\dot{\varepsilon}_{0}$ is the reference strain rate, $\dot{\varepsilon}_{0}=1.0 \mathrm{~s}^{-1}$. $A, D, B, N$, and $C$ are the parameters of the material constitutive model, damage factor, normalized cohesive strength, normalized pressure hardening coefficient, pressure hardening coefficient, and strain rate hardening coefficient, respectively.

Damage factor $D(0 \leq D \leq 1)$ is the accumulation of equivalent plastic strain and the volume strain, and the damage factor is a function of plastic volume strain, equivalent volume strain, and pressure $(P)$, as follows:

$$
D=\sum \frac{\Delta \varepsilon_{p}+\Delta \mu_{p}}{\varepsilon_{p}^{f}+\mu_{p}^{f}},
$$

in which $\Delta \varepsilon_{p}$ is the equivalent plastic strain increment, $\Delta \mu_{p}$ is the equivalent volume strain increment, $\left(\varepsilon_{p}^{f}+\mu_{p}^{f}\right)$ is the plastic strain of fracture as atmospheric pressure $P$.

$$
f(P)=\varepsilon_{p}^{f}+\mu_{p}^{f}=D_{1}\left(P^{*}+T^{*}\right)^{D_{2}},
$$

in which $T^{*}$ is the normalized maximum tensile hydrostatic pressure that the material has, $T^{*}=T / \dot{f}_{c}$, and $D_{1}$ and $D_{2}$ are the damage constant.

The formula (3) describes the processing of material from plastic strain to fracture under continuous pressure $P$, 


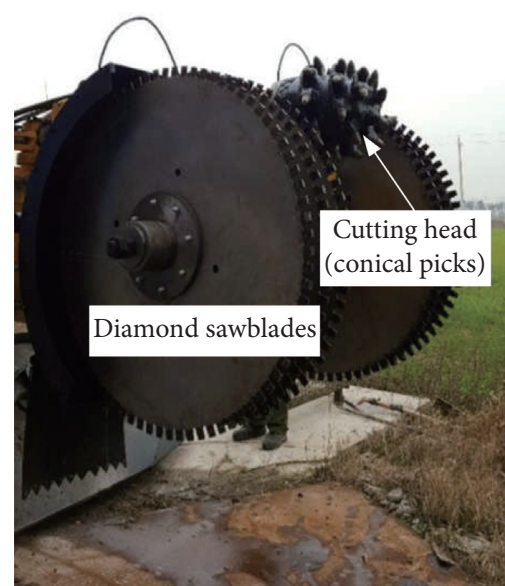

(a)

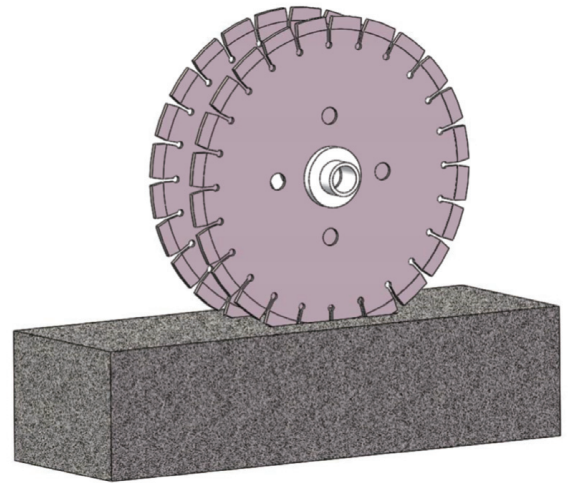

(b)

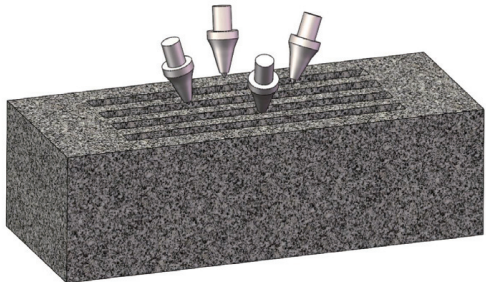

(c)

FIGURE 1: Rock breaking machine combination of diamond sawblades and conical picks: (a) the diamond sawblades and conical picks combined roadheader prototype, (b) the diamond sawblades cutting rock model, and (c) the conical picks cutting rock arc rock plate.

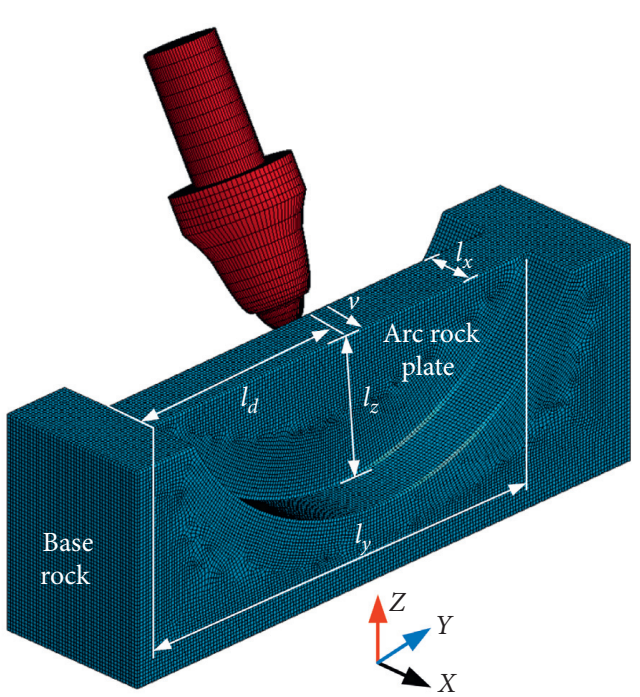

(a)

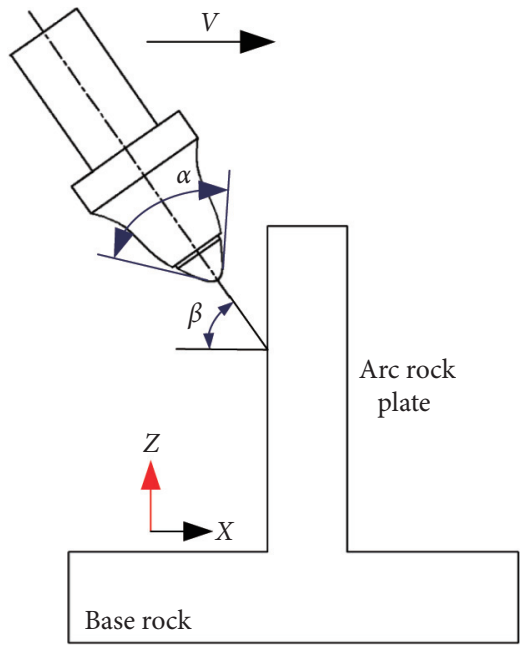

(b)

FIGURE 2: The numerical simulation model of conical pick cutting arc rock plate.

TABLE 1: The key parameters of the JHC constitutive model.

\begin{tabular}{lccccccccc}
\hline$R_{0}\left(\mathrm{~kg} \cdot \mathrm{m}^{-3}\right)$ & $G(\mathrm{~Pa})$ & $A$ & $B$ & $C$ & $N$ & $F_{c}(\mathrm{~Pa})$ & $T(\mathrm{~Pa})$ & $\dot{\varepsilon}_{0}$ & \multicolumn{1}{c}{${ }^{2}$} \\
\hline 2720 & $2.375 e 10$ & 0.79 & 1.6 & 0.007 & 0.61 & $1.21 e 8$ & $7.8 e 6$ & $1 e-6$ & 0.01 \\
\hline$\sigma_{f, \max }$ & $P_{c}(\mathrm{~Pa})$ & $\mu_{c}$ & $P_{\text {lock }}(\mathrm{Pa})$ & $\mu_{\text {lock }}$ & $D_{1}$ & $D_{2}$ & $K_{1}$ & $K_{2}$ \\
\hline 7 & $5.7 e 8$ & 0.01 & $8 e 8$ & 0.08 & 0.04 & 1.0 & $8.5 e 10$ & $1.71 e 10$ & $2.08 e 10$ \\
\hline
\end{tabular}

TABLE 2: Mechanical properties parameters of the rock [24].

\begin{tabular}{|c|c|c|c|c|c|c|}
\hline Properties & $\begin{array}{l}\text { Density } \\
\left(\mathrm{kg} / \mathrm{m}^{3}\right)\end{array}$ & $\begin{array}{l}\text { Poisson's } \\
\text { ratio }\end{array}$ & $\begin{array}{c}\text { Elastic modulus } \\
(\mathrm{GPa})\end{array}$ & $\begin{array}{c}\text { Compression strength } \\
(\mathrm{MPa})\end{array}$ & $\begin{array}{c}\text { Tensile strength } \\
(\mathrm{MPa})\end{array}$ & Shear strength $(\mathrm{MPa})$ \\
\hline Sandstone-1 & 2650 & 0.20 & 17.0 & 113.6 & 6.6 & 13.7 \\
\hline Sandstone-2 & 2670 & 0.29 & 28.0 & 173.7 & 11.6 & 22.4 \\
\hline Sandstone-3 & 2670 & 0.25 & 33.3 & 87.4 & 8.3 & 14.0 \\
\hline Limestone & 2720 & 0.20 & 57.0 & 121.0 & 7.8 & 15.4 \\
\hline
\end{tabular}


and the plastic strain increases with the increase of $T^{*}$. While $P^{*}=T^{*}$, the material cannot support any plastic strain. Damage constant $\varepsilon_{f \text { min }}$ is the minimum plastic strain allowed for material breaking. It can be seen from equations (2) and (3) that, due to the continuous destruction of the internal pores of the material in the process of compression, the cohesive strength of the material is lost, so in most cases, the damage of the material is mainly caused by plastic volume strain.

The JHC model describes the relationship between the hydrostatic pressure and volume strain of the material by the piecewise equation of state.

The first stage is linear elastic stage $\left(P \leq P_{\text {crush }}\right)$, in which hydrostatic pressure and volume strain are linear, and the relationship is described as follows:

$$
P=K_{e} \mu,
$$

in which $K_{e}$ is the bulk modulus, $K_{e}=P_{\text {crush }} / \mu_{\text {cruck }}$, among that, $P_{\text {crush }}$ and $\mu_{\text {cruck }}$ are the crushing volume pressure and the crushing volume strain in the uniaxial compression experiment.

The second stage is the plastic transition stage ( $P_{\text {crush }} \leq P \leq P_{\text {lock }}$ ); the material is compressed and produces plastic deformation, and the formula is as follows:

$$
P=\frac{\left(P_{\text {lock }}-P_{\text {crush }}\right)\left(\mu-\mu_{\text {lock }}\right)}{\mu_{\text {lock }}-\mu_{\text {crush }}},
$$

in which $P_{\text {lock }}$ is the compaction volume pressure ( $\left.\mathrm{MPa}\right), \mu$ is the standard volume strain, and $\mu_{\text {lock }}$ is the compaction volume strain.

The third stage is the fully dense stage $\left(P \geq P_{\text {lock}}\right)$; this stage simulates the material fully compacted, and the formula is as follows:

$$
P=K_{1} \bar{\mu}+K_{2} \bar{\mu}^{2}+K_{3} \bar{\mu}^{3}
$$

in which $\bar{\mu}$ is the corrected volume strain, $\bar{\mu}=\left(\mu-\mu_{\text {lock }} / 1\right.$ $\left.+\mu_{\text {lock }}\right) ; K_{1}, K_{2}$, and $K_{3}$ are the material constant.

2.3. Calibration and Verification. The numerical simulation results of conical pick cutting arc rock plate are compared with experimental results to verify the numerical simulation models. The experimental results of conical pick cutting arc rock plate, with width of $360 \mathrm{~mm}$, height of $80 \mathrm{~mm}$, and thickness of $22 \mathrm{~mm}$ and cutting speed of $2 \mathrm{~m} / \mathrm{min}$, cutting angle of $50^{\circ}$, and distance of cutting point to arc rock plate central axis of $1 / 2$, are shown in Figures 3 and 4 . The arc rock plate cracks of the experiments and numerical simulation are similar. And the peak cutting forces of the experimental and the numerical simulation are 2196.1 and $2246.5 \mathrm{~N}$, respectively, as shown in Figure 4. There is less difference between experimental and numerical simulation. The results indicate that the numerical simulation results are in agreement with experimental results, which proves that the numerical simulation is reliable in the paper.

\section{Results and Discussion}

3.1. Process of Conical Pick Cutting Arc Rock Plate. The results of conical pick cutting arc rock plate, with width of $420 \mathrm{~mm}$, height of $80 \mathrm{~mm}$, and thickness of $30 \mathrm{~mm}$ and cutting speed of $2 \mathrm{~m} / \mathrm{min}$, cutting angle of $50^{\circ}$, and distance of cutting point to arc rock plate central axis being $l_{d} / l_{y}=1 / 2$, are illustrated in Figures 5 and 6 . Conical pick cuts arc rock plate with uniform linear motion along the $x$-axial direction. The conical pick crushes the arc rock plate where the contacting position, which is affected by cutting force while the pick contacting and squeezing, as shown in Figure 5(a). The conical pick continues to cut the arc rock plate with moving forward. The main cracks appear at the contacting position of the arc rock plate and the joint of arc rock plate and base rock, as displayed in Figure 5(b). The main cracks of the contacting position between conical pick and arc rock plate and the connection between the arc rock slab and base rock extends to branch cracks, as shown in Figure 5(c). With the cutting force increasing, the cracks of the contacting position between conical pick and rock plate and the joint between arc rock plate and base rock continues to extend and form a large number of branching cracks. The cracks' intersection causes the rock plate breaking, forming rock fragments, as illustrated in Figure 5(d). The cutting force curve of conical pick is shown in Figure 6, which is consisted of four stages corresponding to the four stages of conical pick cutting arc rock plate. The conical pick contacts the arc rock plate with great impact force reaching the failure strength of some rock elements, making the crag of arc rock plate crumbles and the cutting force decreases sharply. The conical pick continues to cut arc rock plate, and the deformation amount of arc rock plate increases with the increase of cutting force. With the conical pick cutting the arc rock plate, the main cracks begin to appear at the connection between arc rock plate and base rock whose intersection causes rock fragments appearing in the arc rock plate; meanwhile, the cutting force decreases. The conical pick continues cutting arc rock plate, causing the cracks to keep growing through arc rock plate forming fragments and the arc rock plate breaking.

Because rock is quasibrittle material with low strain, the arc rock plate appears damaged while the initial stage of conical pick contacting the rock plate with uniform linear speed. Conical pick cuts forward continuously while contacting the rock plate; the elastic and plastic deformation of arc rock plate increases and reaches the failure criterion, and the arc rock plate forms the main crack. While the conical pick continues to cut the arc rock plate, the principal cracks of the arc rock plate expand and form a great number of brand cracks. The arc rock plate forms many fragments and breaks into rock block with the branch cracks expanding and intersecting. The cutting force raises from 0 to a certain value and decreases sharply while the conical pick striking the arc rock plate. The cutting force rises while the pick contacting the arc rock plate and then the arc rock plate forms the main cracks, and the cutting force reduces, caused by some rock elements' failure and deletion in the position of conical pick contacting arc rock plate. The cutting force of conical pick increases with conical pick continuous cutting; however, the 


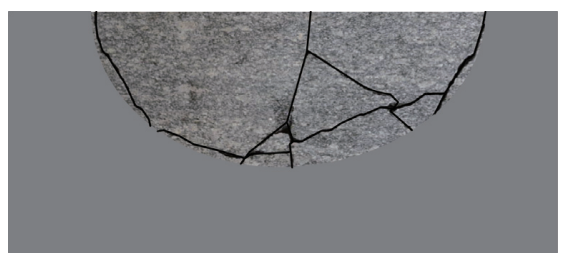

(a)

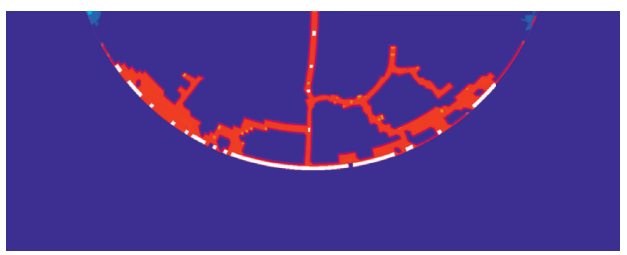

(b)

FIGURE 3: The arc rock plate breaking results of experiments and numerical simulation. (a) The arc rock plate breaking results of experiment. (b) The arc rock plate breaking results of numerical simulation.

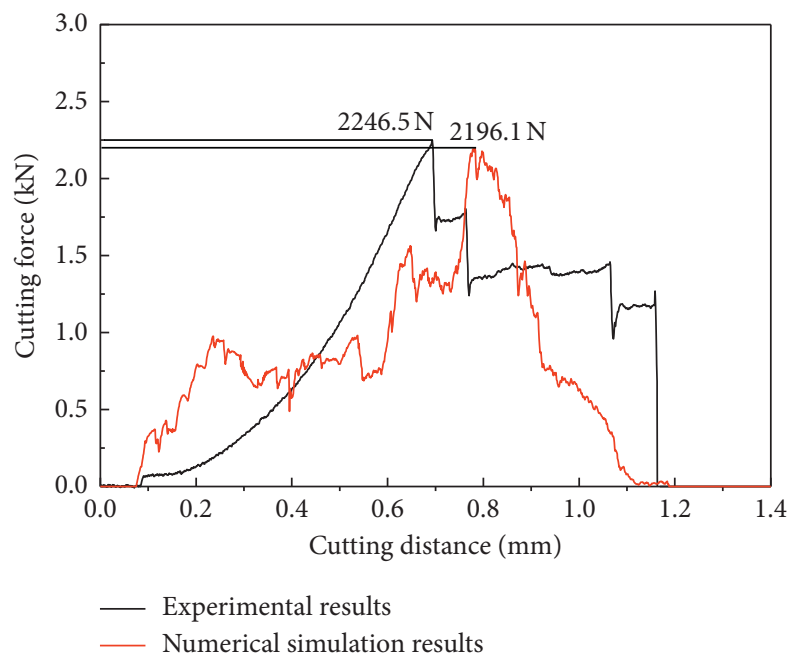

FIgURE 4: The cutting force of experimental and numerical simulation.

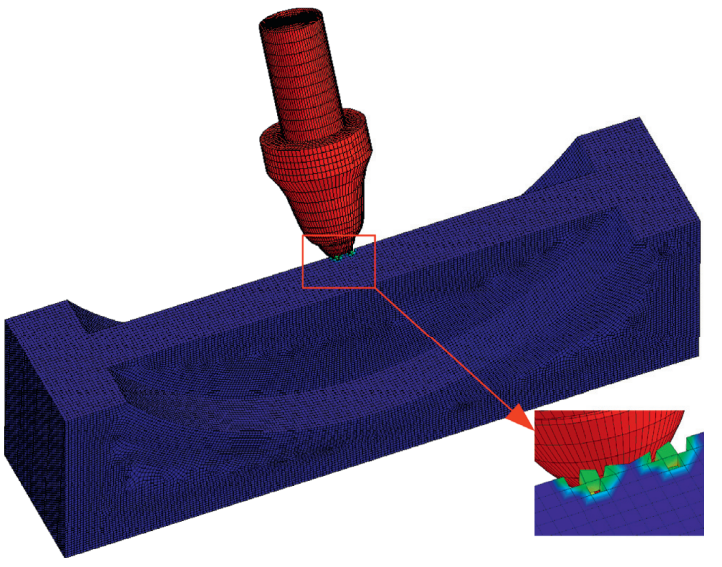

(a)

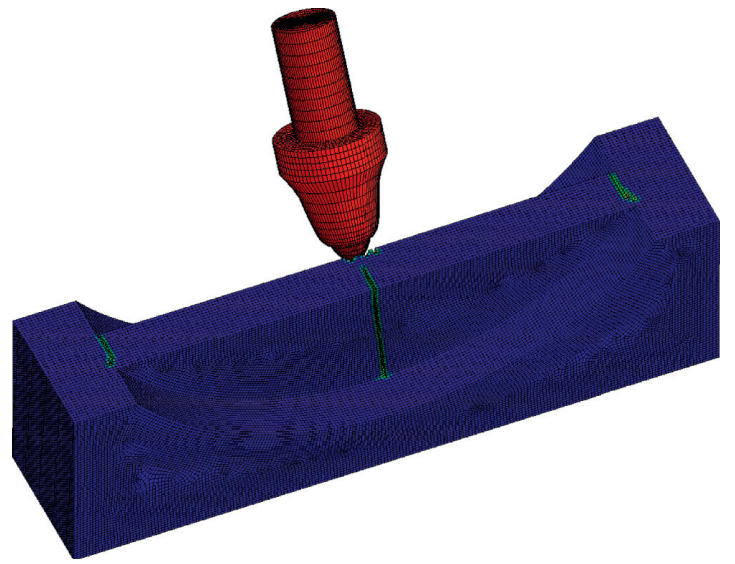

(b)

FIGURE 5: Continued. 


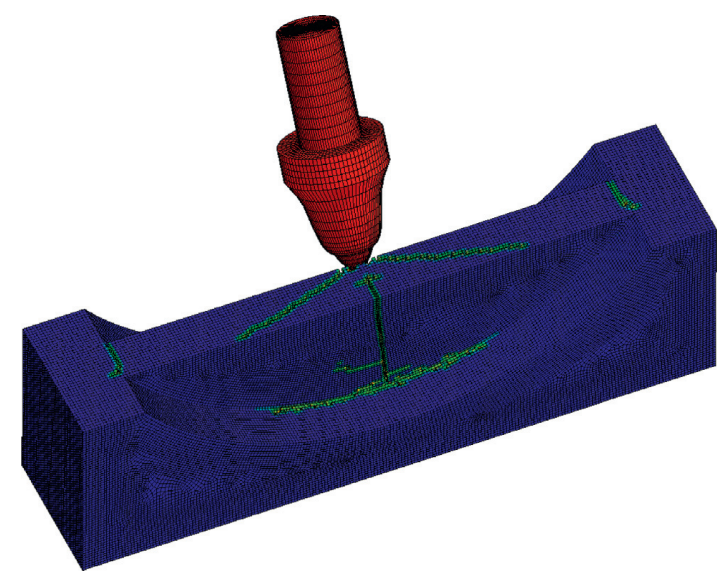

(c)

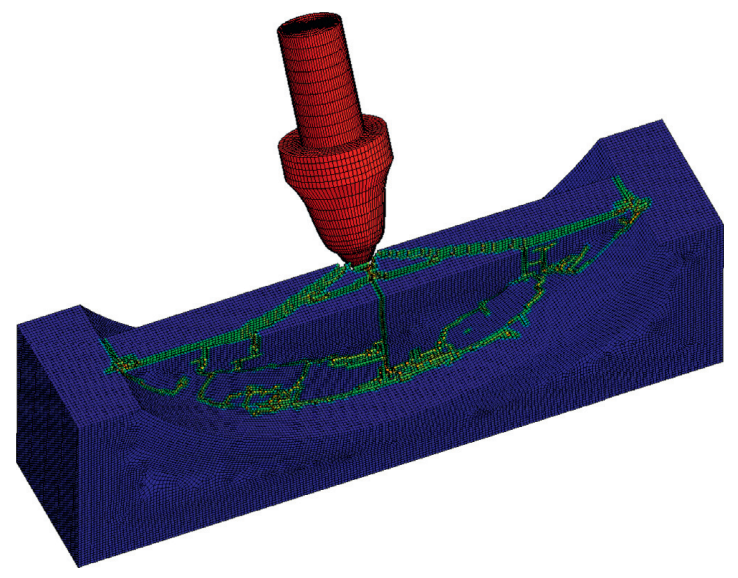

(d)

Figure 5: The process of conical pick cutting arc rock plate. (a) Conical pick contacting the arc rock plate. (b) Main cracks generation. (c) Propagation into branch cracks. (d) Cracks connection and fragments separation.

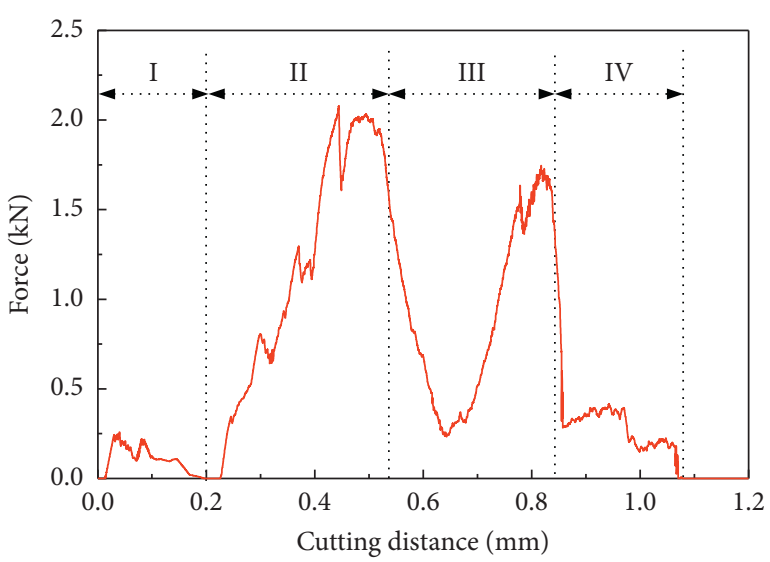

FIGURE 6: Variation on cutting force with cutting distance.

force decreases while the main cracks expand to form branch cracks and form rock fragments.

\subsection{Influence of Variations on Arc Rock Plate Cracks}

3.2.1. Influence of Height on Arc Rock Plate Cracks. The results of conical pick cutting arc rock plate, with width of $420 \mathrm{~mm}$, thickness of $30 \mathrm{~mm}$, and height of $40,50,60,70$, and $80 \mathrm{~mm}$ and cutting speed of $2 \mathrm{~m} / \mathrm{s}$, cutting angle of $50^{\circ}$, and $l_{d} / l_{y}=1 / 2$, are shown in Figure 7 . The main cracks appear at the contacting position between the conical pick and arc rock plate and the connecting position between arc rock plate and basic rock. The main cracks propagate and produce the branch cracks, and the cracks intersect, forming rock fragments and the arc rock plate breaking. The cracks propagating situation of the arc rock plate are shown in Figures $7(\mathrm{a})-7(\mathrm{~d})$. The arc rock plate is broken from the joint between the arc rock plate and basic rock. The size and shape of the rock fragments are random. It can be concluded that the range of cracks outward propagation increased with the increase of arc rock plate height; however, the correlation between breakage range and height of arc rock plate is strong. There are some cracks extending from the arc rock plate to base rock when the height is reaching certain values. The upper surface of base rock is broken greatly when the height reaches $80 \mathrm{~mm}$.

3.2.2. Influence of Width on Arc Rock Plate Cracks. The results of the numerical simulation about conical pick cutting arc rock plate are shown in Figure 8, with height of $80 \mathrm{~mm}$, thickness of $30 \mathrm{~mm}$, and width of $240,300,360$, and $420 \mathrm{~mm}$, respectively, with cutting speed of $2 \mathrm{~m} / \mathrm{min}$, cutting angle of $50^{\circ}$, and $l_{d} / l_{y}$ of $1 / 2$. The arc rock plate is fractured from the connection between arc rock plate and basic rock. The range of cracks propagating from the upper part of the arc rock plate to the base rock increases, with the increase of the arc rock plate width. The fracture of the arc rock plate is shown in Figures $8(a)-8(d)$. The width of arc rock plate has great influence on rock cracks and cutting force. The deformation of arc rock plate is closely linked to the arc rock plate width. Because of the constant height and thickness of arc rock plate, the effect of the width on the deformation of the plate and the maximum mean peak cutting force decrease with the arc rock plate width enlarging.

\subsubsection{Influence of Thickness on Arc Rock Plate Cracks.} The numerical simulation results of conical pick cutting arc rock plate are shown in Figure 9, with height of $80 \mathrm{~mm}$, width of $420 \mathrm{~mm}$, and thickness of $14,18,22,26$, and $30 \mathrm{~mm}$ with cutting speed of $2 \mathrm{~m} / \mathrm{min}$, cutting angle of $50^{\circ}$, and $l_{d} / l_{y}=1 / 2$. The conical pick cutting rock plate leads to the arc rock plate forming cracks and where the conical pick contacting the arc rock plate. The main cracks are formed and propagated in the middle of the arc rock plate front surface and joint of the arc rock plate and base rock and then the main cracks expand to form the branch cracks. Rock fragments form and fall down while the crack intersecting. While the thickness of the arc rock plate becomes larger, there would be more radial cracks in the upper part of the 


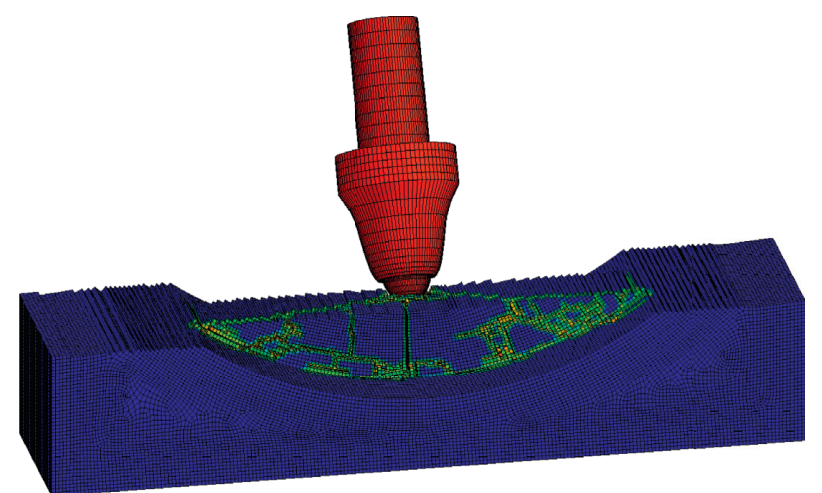

(a)

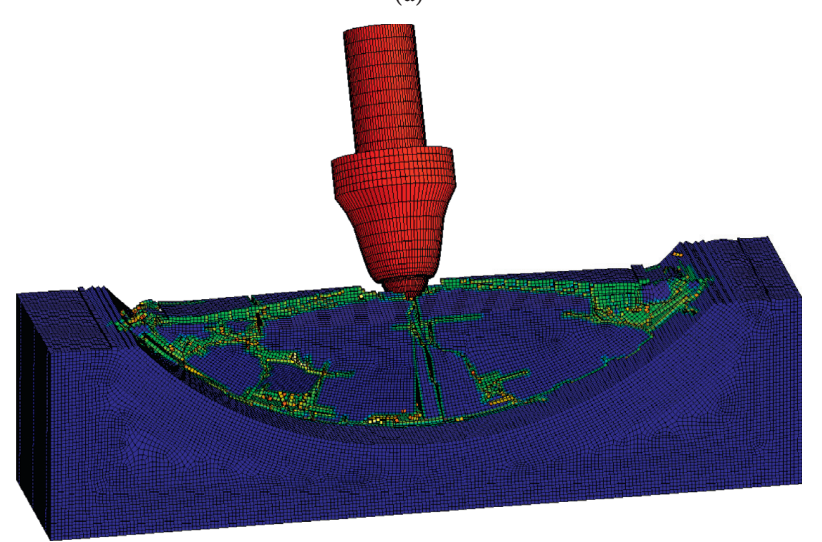

(c)

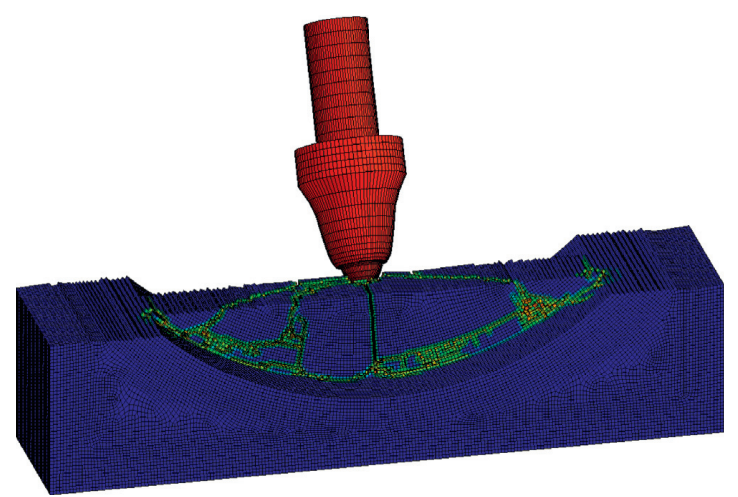

(b)

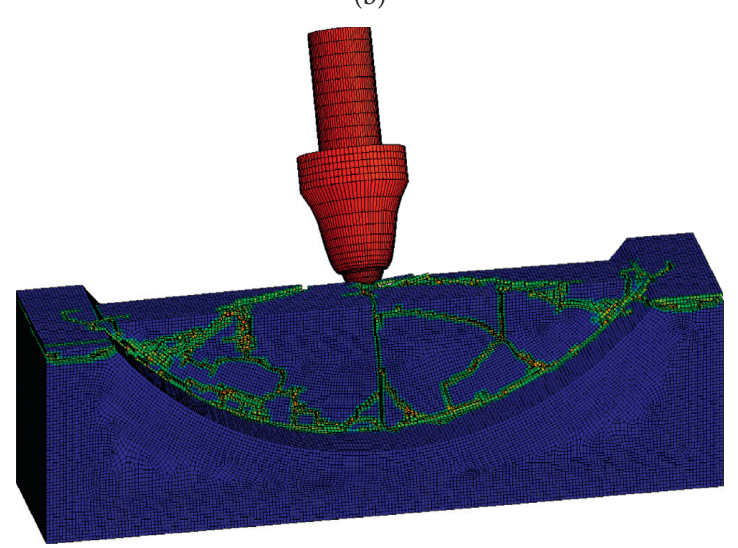

(d)

FIgURE 7: The cutting results with various heights of arc rock plate.

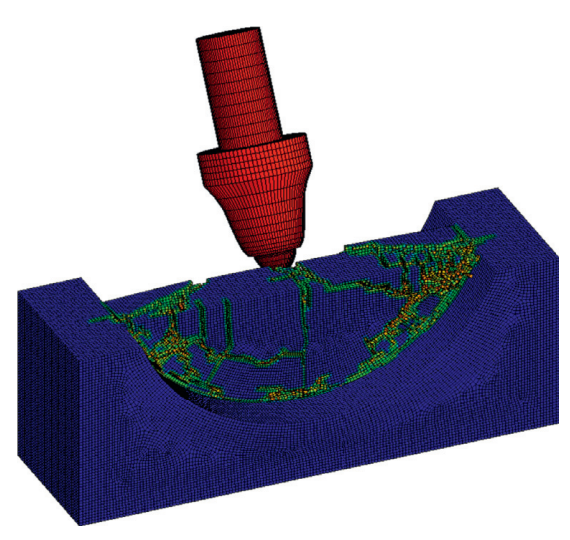

(a)

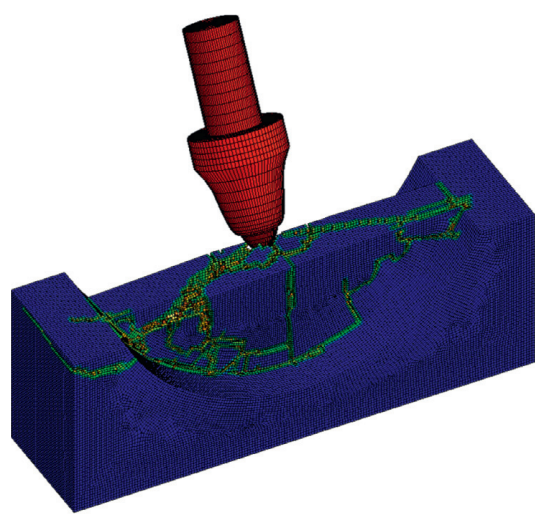

(b)

FIgUre 8: Continued. 


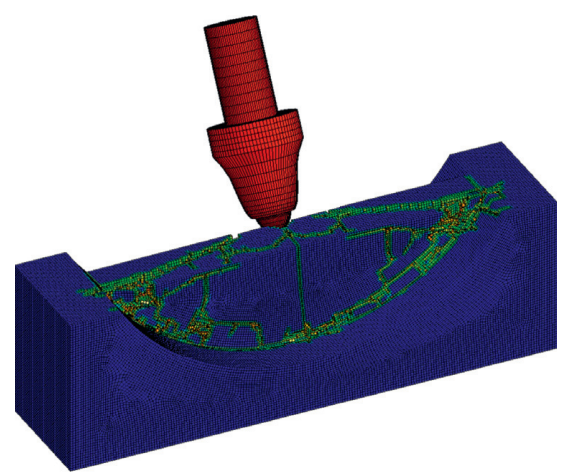

(c)

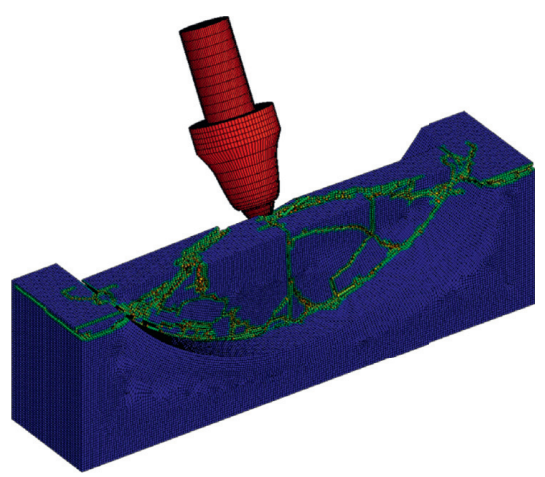

(d)

FIGURE 8: The cutting results of conical pick cutting arc rock plate with various width.

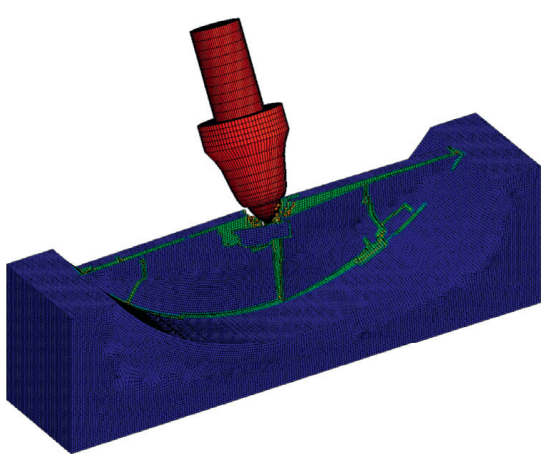

(a)

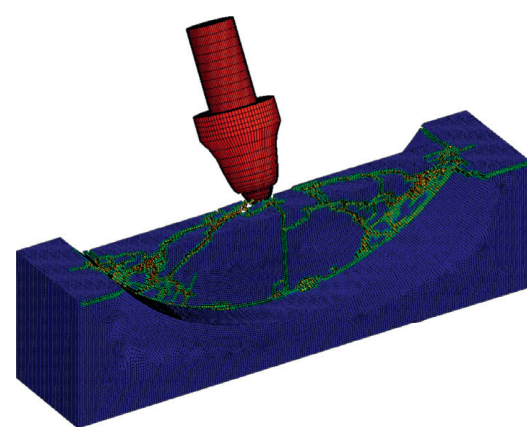

(d)

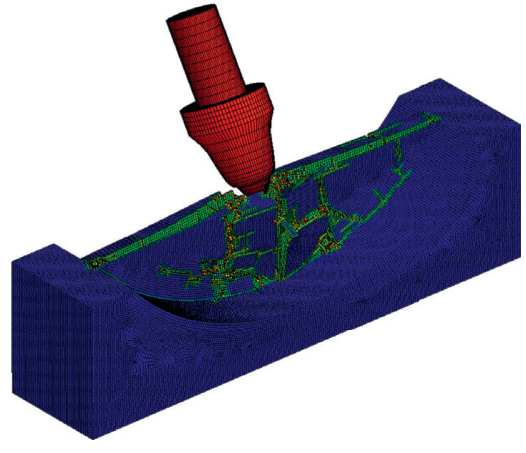

(b)

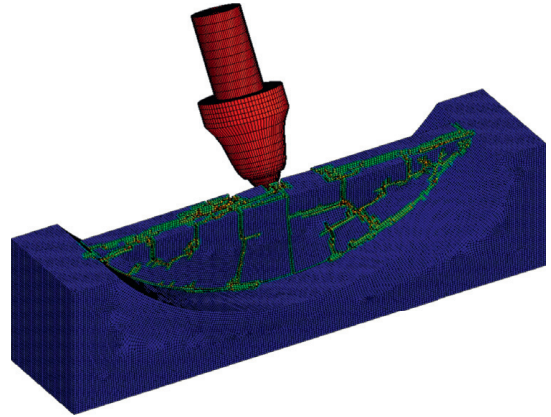

(c)

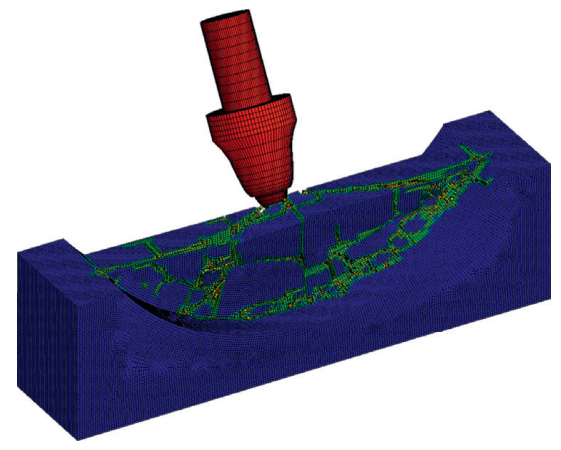

(e)

FIGURE 9: Numerical simulation results of conical pick cutting arc rock plate with various thickness.

rock plate where the position of the pick initially contacting. And the main cracks which are at the position of the front surface and the junction of the plate and base rock grow to form multiple branch cracks which intersect to form the fragments. The numerical simulation results show that with the increase of arc rock plate rock thickness, the number of cracks increased; however, the volume of fractures decreases and the cracks propagates range to basic rock.

3.2.4. Influence of Cutting Angle on Arc Rock Plate Cracks. The numerical simulation results of conical pick cutting arc rock plate, with cutting angles of $30^{\circ}, 35^{\circ}, 40^{\circ}, 45^{\circ}$, and $50^{\circ}$, width of $420 \mathrm{~mm}$, height of $80 \mathrm{~mm}$, feed speed of $2 \mathrm{~m} / \mathrm{min}$, and $l_{d} / l_{y}$ of $1 / 2$, are shown in Figures 10(a)-10(e). Comparing the numerical simulation results with various cutting angles of conical pick, it can be clearly detected that cutting angle has greater impact on the cracks of rock plate. Figure 10(a) shows that the conical pick cutting arc rock plate is with angle of $30^{\circ}$, and it is obvious that there are too many breach creaks expanding from the main cracks. There are too many small rock fragments and less big rock fragments, and the distribution of rock fragments is that the larger rock fragments near the middle of the arc rock plate and the rock fragments near the edge are smeller. Observing the damage cloud figures as shown in Figures 10(b)-10(e), 


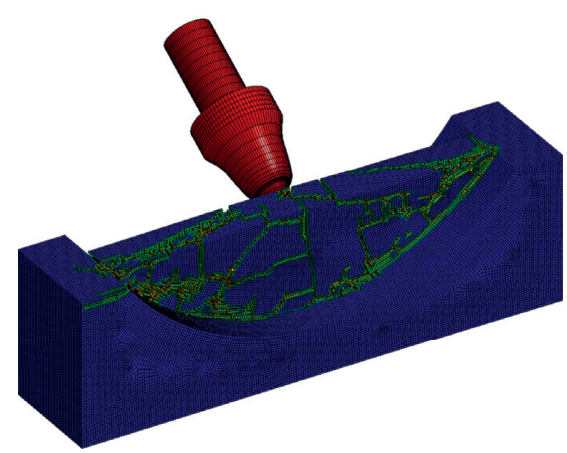

(a)

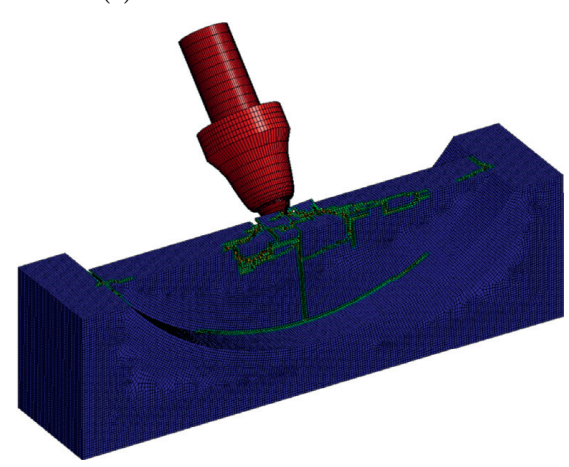

(d)

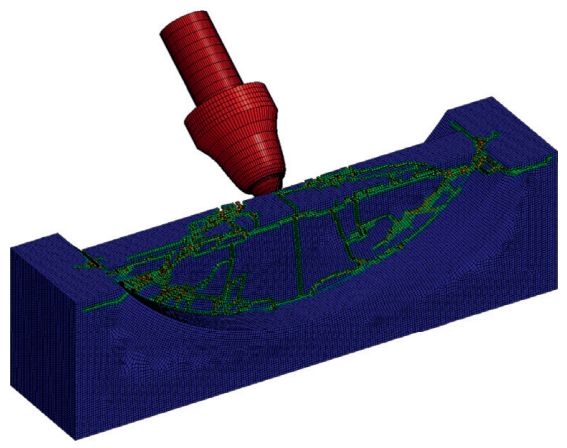

(b)

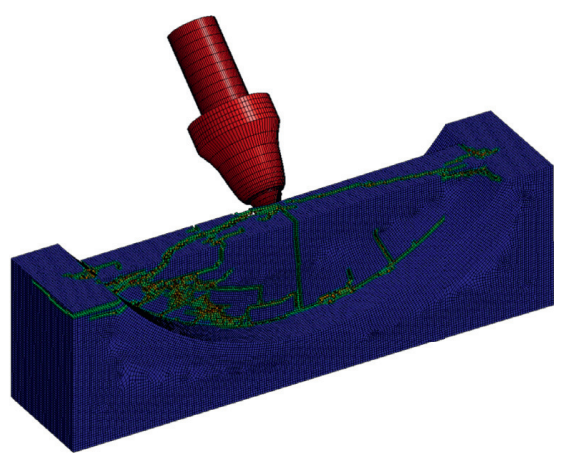

(c)

FIGURE 10: The numerical simulation of conical pick with various cutting angles cutting arc rock plate.

the number of rock fragments decreases with the cutting angle increasing. The volume of rock fragments and the breaking range of the rock plate decreases with the cutting angle of the pick increasing.

\subsubsection{Influence of Cutting Point to Arc Rock Plate Central} Plate Distance on Cracks. The results of the conical pick cutting arc rock plate with width of $420 \mathrm{~mm}$, height of $80 \mathrm{~mm}$, and thickness of $30 \mathrm{~mm}$ and different distances of cutting point to arc rock plate central axis which are $1 / 8,1 / 4$, $3 / 8$, and $1 / 2$, are indicated in Figure 11 . The conical pick is closer to the edge of arc rock plate, there are less cracks on the arc rock plate, and the rock fracture range of the arc rock plate is smaller. The cracks of the arc rock plate are random, and the size of the broken rock block is uncertain. When the conical pick is far from the center of the arc rock plate, the main cracks appear at contacting position between conical pick and arc rock plate and extend to the center of plate and the joint of the rock plate and basic rock. However, when $l_{d} / l_{y}=1 / 2$, the breakage of rock plate is ideal. The arc rock plate can be completely broken and fragments around the pick are smaller, but the rock fragments far from the conical pick are larger. Besides, $l_{d} / l_{y}=1 / 2$, the larger rock fragments are near the conical pick, and the smaller rock fragments are near the arc rock plate edge.

3.2.6. Influence of Cutting Speed on Arc Rock Plate Cracks. The numerical simulation results of conical pick cutting arc rock plate, with width of $420 \mathrm{~mm}$, height of $80 \mathrm{~mm}$, and thickness of $30 \mathrm{~mm}$, with cutting angle of $50^{\circ}, l_{d} / l_{y}=1 / 2$, and cutting speeds of $1 \mathrm{~m} / \mathrm{s}, 2 \mathrm{~m} / \mathrm{s}$, and $3 \mathrm{~m} / \mathrm{s}$, are shown in Figures 12 and 11(d). It is obvious that the cutting speed influences the number of cracks and the volume of the rock fragments greatly. And the number of cracks increases with the cutting speed increasing. Meanwhile, the number and volume of rock fragments increase.

\subsection{Influence of Variation on Cutting Force}

3.3.1. Influence of Height on Cutting Force. The variation on mean peak force of conical pick cutting arc rock plate with different heights of four kinds of rocks is given in Figure 13. The conical pick cuts arc rock plate with widths of 240, 300, 360 , and $420 \mathrm{~mm}$, heights of $40,50,60,70$, and $80 \mathrm{~mm}$, and thickness of $30 \mathrm{~mm}$, with cutting speed of $2 \mathrm{~m} / \mathrm{min}$, cutting angle of $50^{\circ}$, and $l_{d} / l_{y}=1 / 2$. It can be obvious that with the enlargement of the height, the mean peak cutting force of conical pick cutting arc rock plate decreases and the decrease amplitude decreases tending to stable value. Rock types have huge influence on the mean peak cutting force of arc rock plate, and the correlation between mean peak cutting force and rock types is closely related, as shown in Figure 13.

3.3.2. Influence of Width on Cutting Force. The conical pick cuts arc rock plate with thickness of $30 \mathrm{~mm}$, width of 240 , 300,360 , and $420 \mathrm{~mm}$, height of $40,50,60,70$, and $80 \mathrm{~mm}$ with the feed speed of $2 \mathrm{~m} / \mathrm{min}$, cutting angle of $50^{\circ}$, and $l_{d} / l_{y}=1 / 2$. From further study of the influence of arc rock plate width on mean peak cutting force, curves of mean peak 


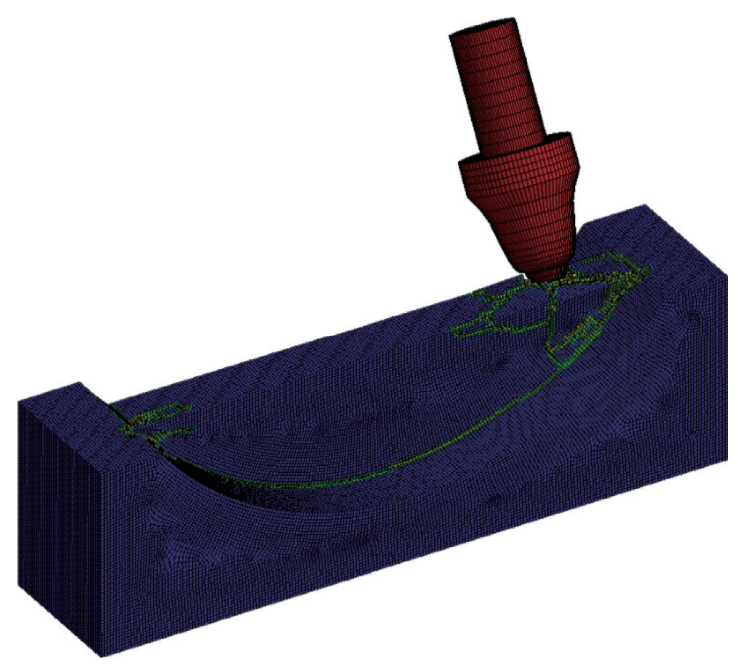

(a)

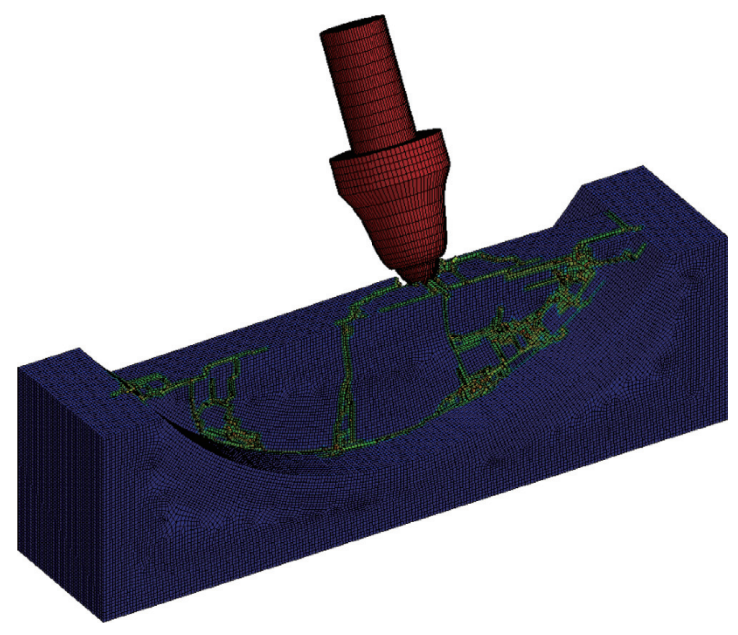

(c)

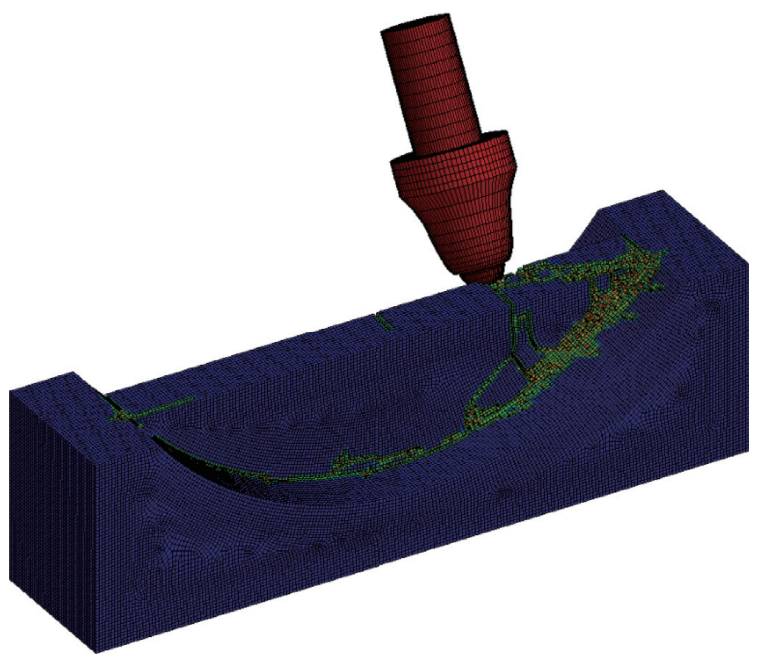

(b)

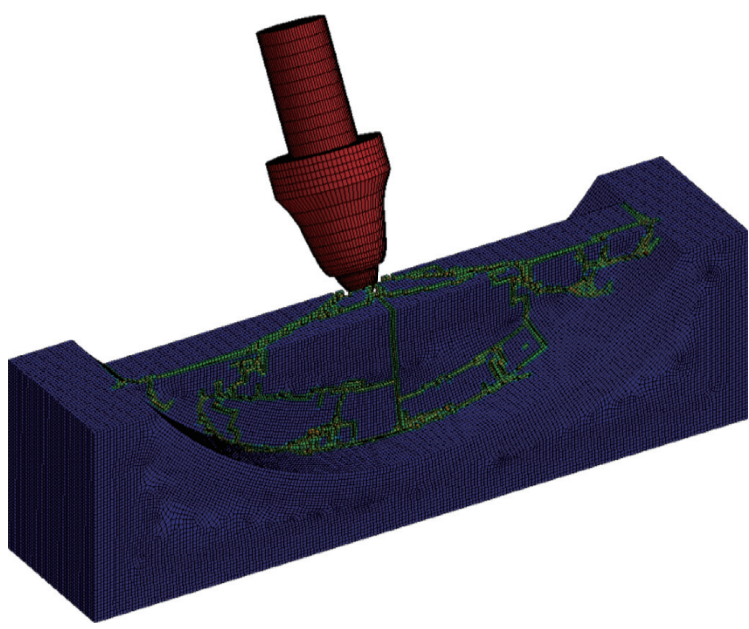

(d)

FIGURE 11: The cutting results of conical pick cutting arc rock plate with different cutting point to arc rock plate central axis distances.

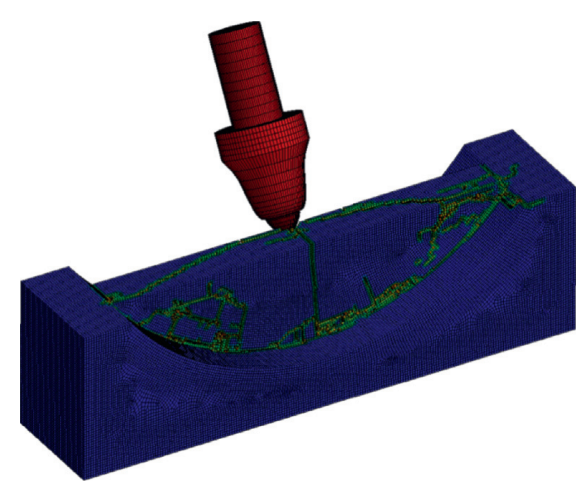

(a)

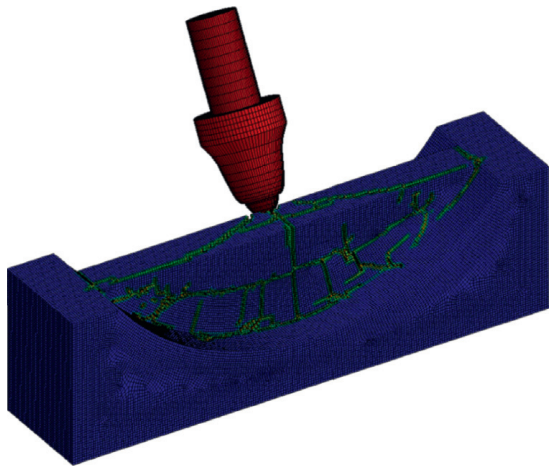

(b)

FIGURE 12: The numerical simulation results of conical pick with various cutting speed cutting arc rock plate.

cutting force with various width are illustrated in Figure 14. The mean peak cutting force decreases with the arc rock plate width increasing. The mean peak cutting force decreases gradually and tends to be stable. It is indicated that the influence of arc rock plate width on cutting force of conical pick cutting arc rock plate decreases and tends to 


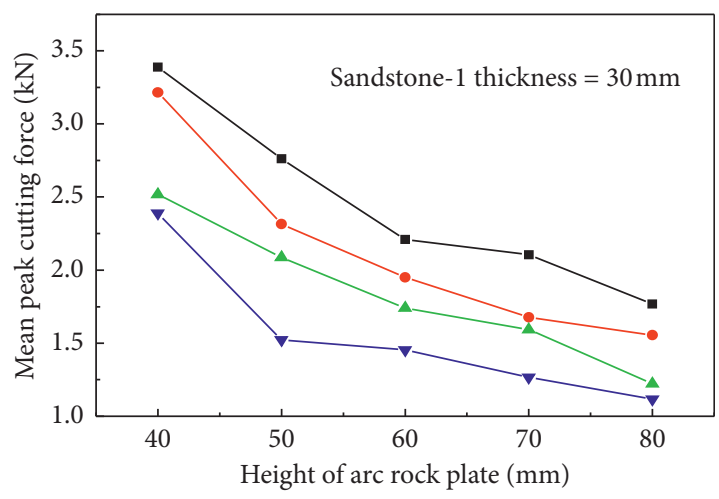

Width

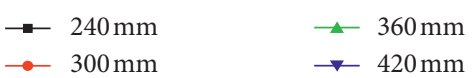

(a)

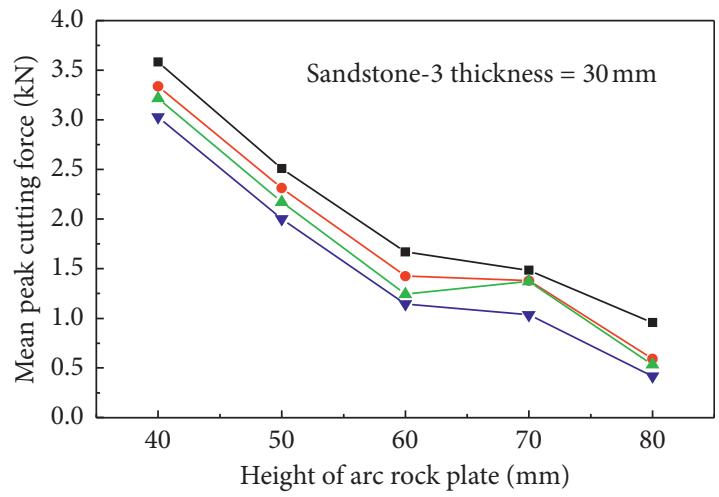

Width

$\rightarrow-240 \mathrm{~mm}$

$\rightarrow 360 \mathrm{~mm}$

$\longrightarrow \quad 420 \mathrm{~mm}$

(c)

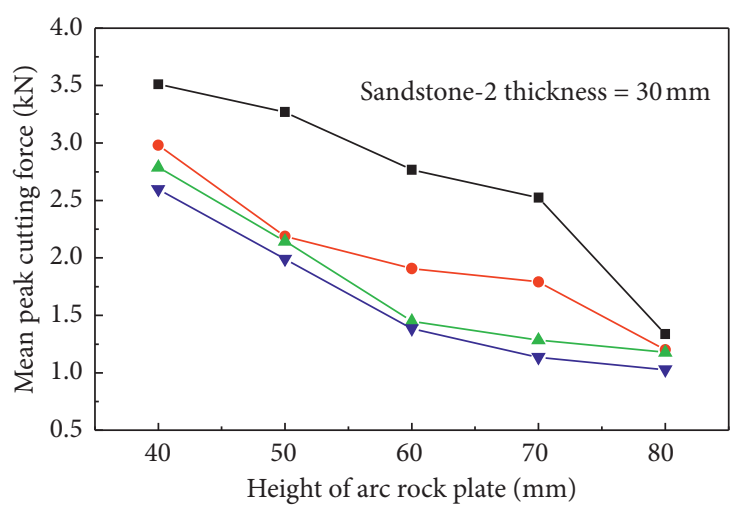

Width

$\rightarrow 240 \mathrm{~mm}$

$\rightarrow 360 \mathrm{~mm}$

$\longrightarrow 300 \mathrm{~mm}$

$\rightarrow \quad 420 \mathrm{~mm}$

(b)

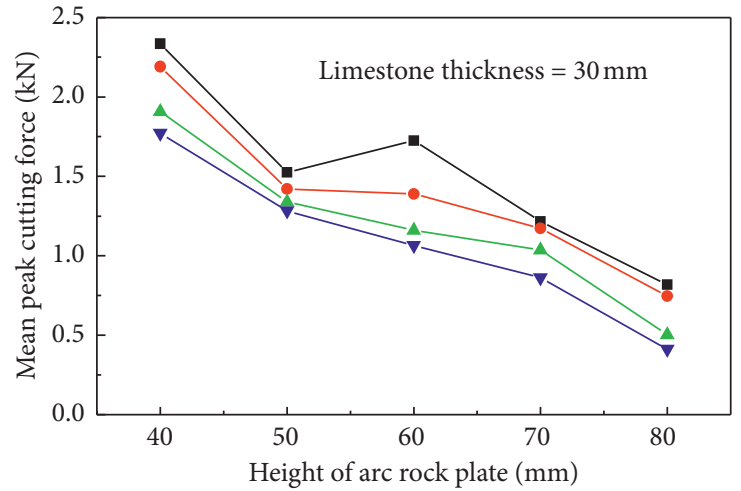

Width

$\rightarrow-240 \mathrm{~mm}$

$-360 \mathrm{~mm}$

$\rightarrow \quad 420 \mathrm{~mm}$

(d)

FIGURE 13: The variation on mean peak cutting force with various height of rock plate.
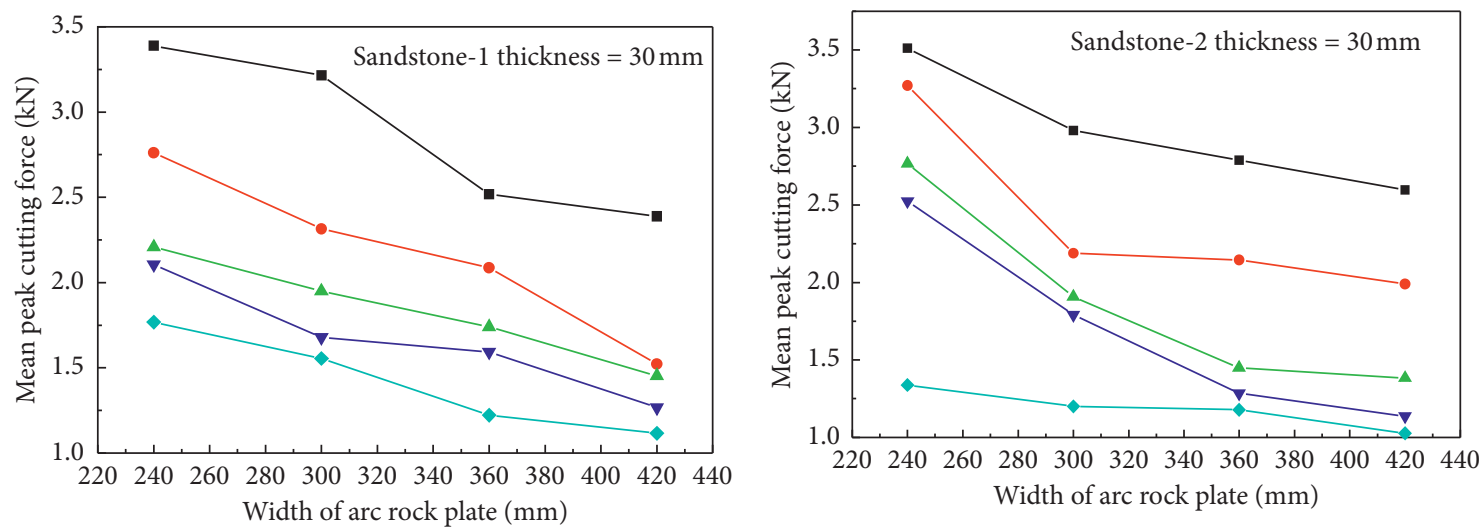

Height

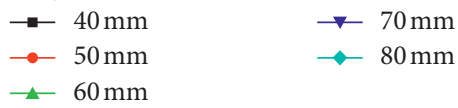

Height

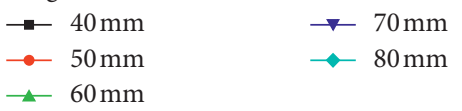

(a)

(b)

Figure 14: Continued. 


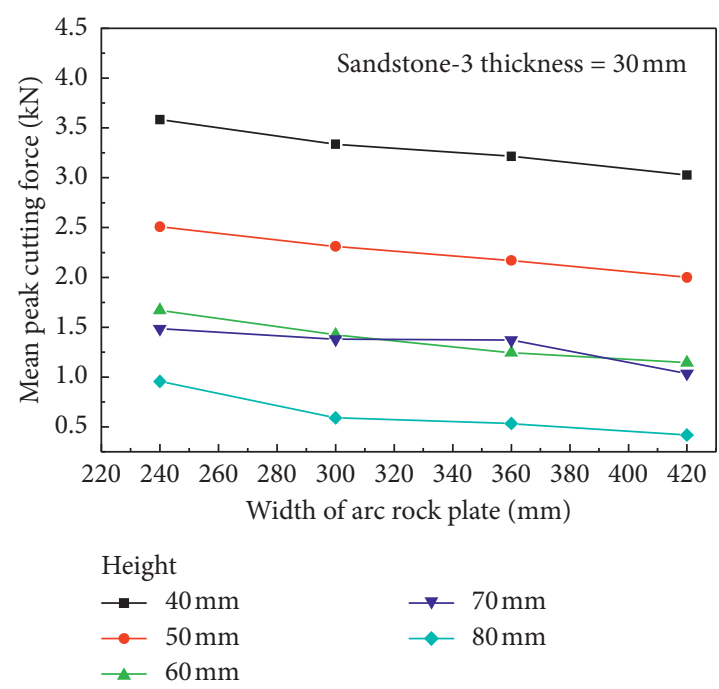

(c)

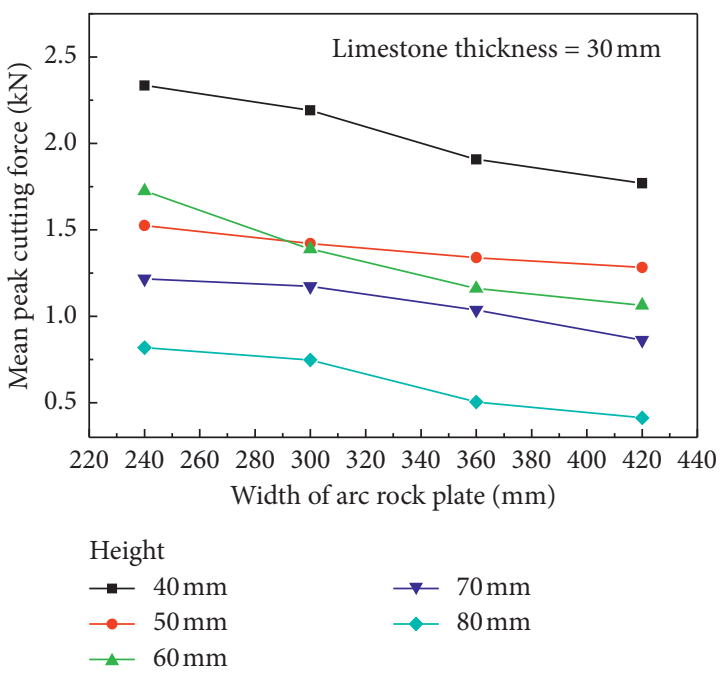

(d)

FIGURE 14: The variation of mean peak cutting force with width of arc rock plate for different rock properties.

stable with the width increasing. Increasing the arc rock plate width is beneficial to decline the cutting force of the conical pick cutting arc rock plate.

3.3.3. Influence of Thickness on Cutting Force. The mean peak cutting force of conical pick cutting arc rock plate is presented in Figure 15. The conical pick cuts arc rock pick with width of $240,300,360$, and $420 \mathrm{~mm}$, height of $80 \mathrm{~mm}$, and thickness of $14,18,22,26$, and $30 \mathrm{~mm}$ with cutting speed of $2 \mathrm{~m} / \mathrm{min}$, cutting angle $50^{\circ}$, and $l_{d} / l_{y}=1 / 2$. The mean peak cutting force increased and growth rate increases with the arc rock plate thickness increasing by comparing the mean peak cutting force curves of four kinds of arc rock plate materials with different thickness. It is obvious that the thickness of arc rock plate has great effect on cutting force. And the relationship between the average peak cutting force and the thickness of arc rock plate is positive exponential relationship.

3.3.4. Influence of Cutting Angle on Cutting Force. The mean peak cutting force curves results of conical pick cutting arc rock plate, with thickness of $30 \mathrm{~mm}$, cutting angle of 30,35 , 40,45 , and $50^{\circ}$, and $l_{d} / l_{y}=1 / 2$, are shown in Figure 16 . It is obvious that the cutting angle influences the mean peak cutting force. The cutting force decreases slowly with the cutting angle increasing and tends to stable. Therefore, increasing the cutting angle can decrease the mean peak cutting force.

\subsubsection{Influence of Cutting Point to Arc Rock Plate Central} Axis Distance on Cutting Force. The mean peak cutting force curves of numerical simulation about conical pick cutting arc rock plate, with cutting speed of $2 \mathrm{~m} / \mathrm{min}$, cutting angle of $50^{\circ}$, and $l_{d} / l_{y}$ of $1 / 8,1 / 4,3 / 8$, and $1 / 2$, are shown in Figure 17 . The mean peak cutting force is influenced greatly by distance of cutting point to arc rock plate central axis. And with the cutting point close to the middle of the arc rock plate, the mean value reduced and the reduction range decreases and tends to be stable and the smallest value appears at the cutting point at the central axis of the arc rock plate.

3.3.6. Influence of Cutting Speed on Cutting Force. The mean peak cutting force curves of numerical simulation about conical pick cutting arc rock plate, with width of $420 \mathrm{~mm}$, height of $80 \mathrm{~mm}$, and thickness of $30 \mathrm{~mm}$, cutting angle of $50^{\circ}, l_{d} / l_{y}=1 / 2$, and cutting speed of $0.5,1.0,1.5,2.0,2.5$, and $3.0 \mathrm{~m} / \mathrm{min}$, are shown in Figure 18. The mean peak cutting force variation with the increase of cutting speed is smaller. While the cutting speed is smaller, the feed speed of conical pick has no obvious influence on the mean peak cutting force. Researching the relationship between mean peak cutting force and cutting speed is meaningless.

3.4. Regression Analysis of Cutting Force and Variation. Multivariate linear regression analysis is to investigate the relationship between multiple independent variables and a dependent variable. It is more effective and predictable to estimable the dependent variable by the optimal combination of multiple independent variables than by only one independent variable. Therefore, multiple linear regression is selected to research the influence of multiple variables on the mean peak cutting force. For the conical pick cutting arc rock plate, mean peak cutting force is considered as a dependent variable, and the structural parameters of arc rock plate and the cutting parameters are independent variables.

The relationship between six independent variables and the mean peak cutting force by the multivariable linear analysis. In order to express the results, the dependent variable (the mean peak cutting force) is denoted by $Y$, and the independent variables are denoted by $X_{a}$ (width of arc 


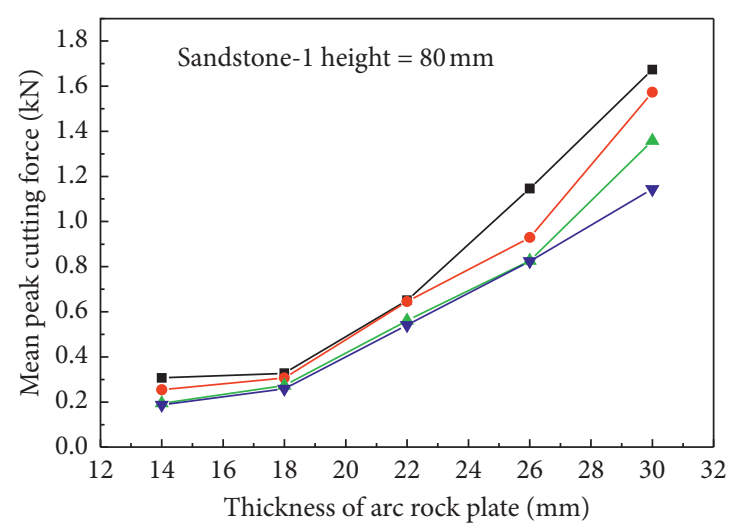

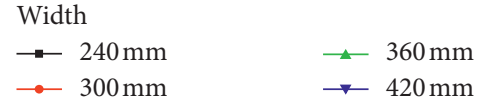

(a)

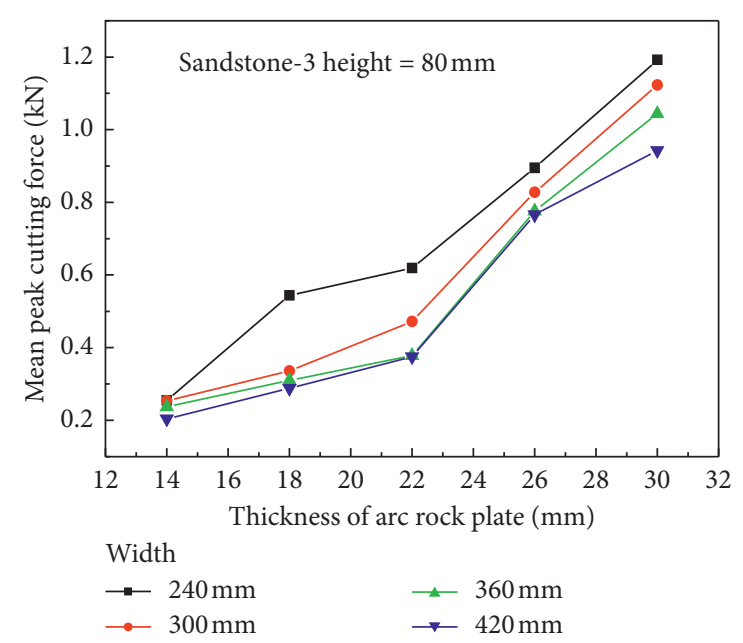

(c)

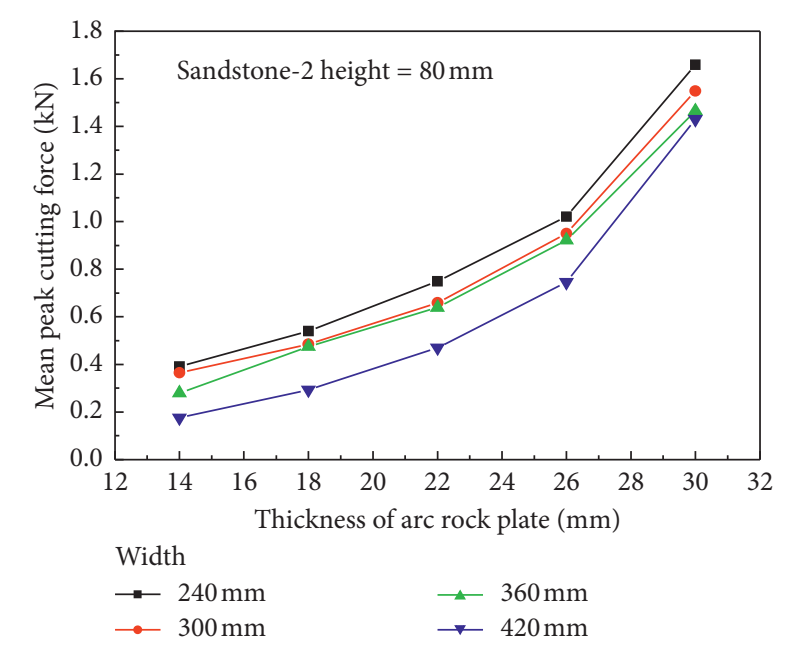

(b)

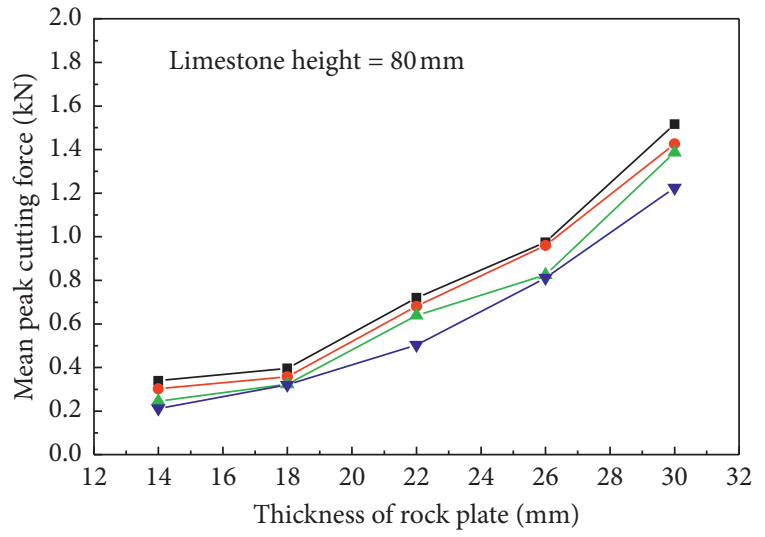

Width

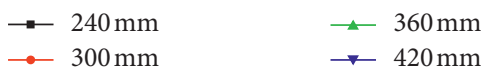

(d)

FIGURE 15: The mean peak cutting force curve with various thickness of arc rock plate.

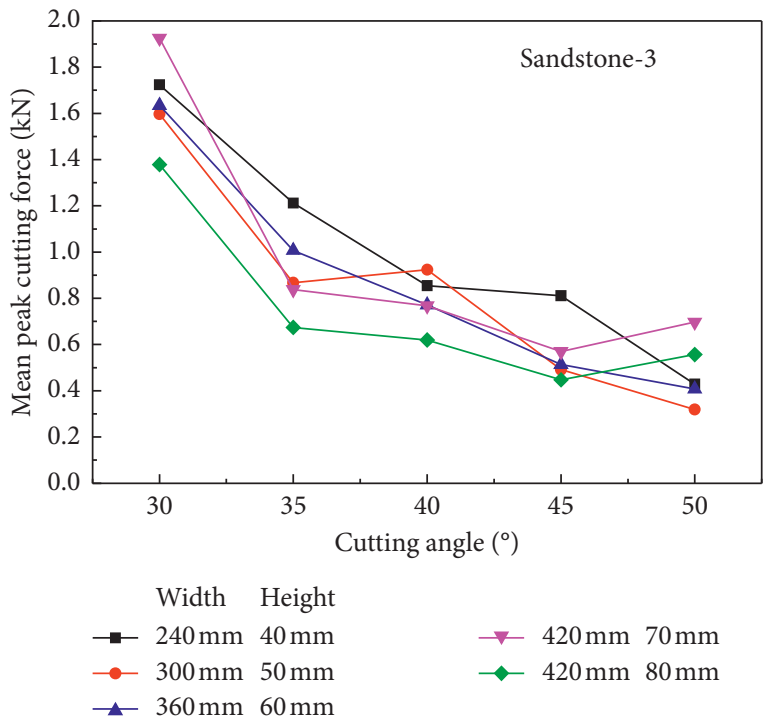

FIGURE 16: The variation of mean peak cutting force with cutting angle.

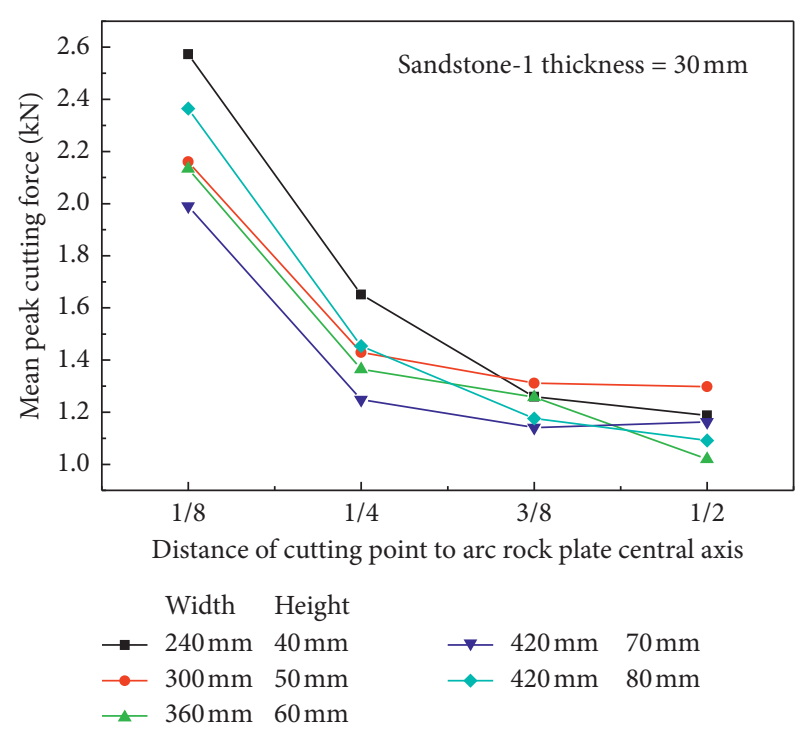

FIGURE 17: The variation of mean peak force with cutting point to arc rock plate central axis distance. 


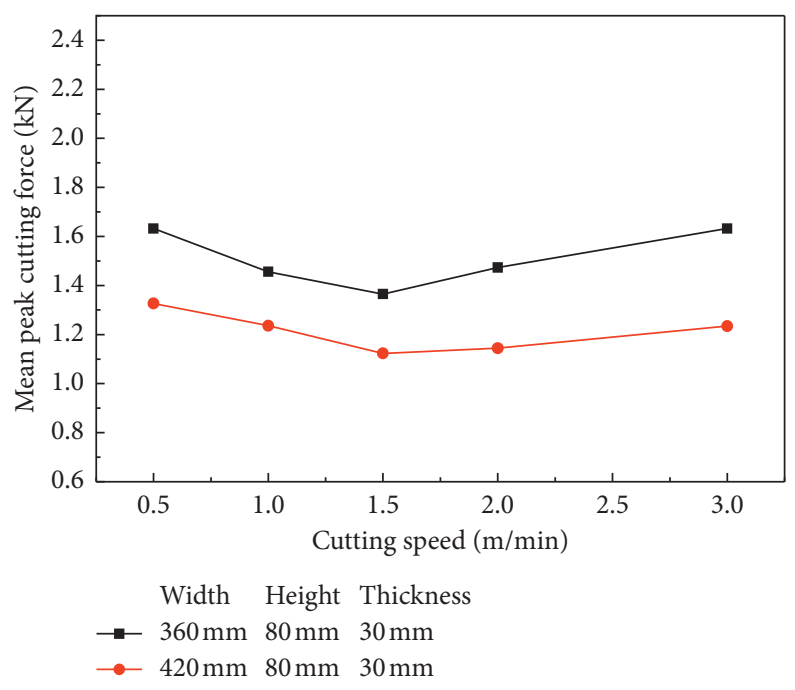

FIGURE 18: The variation of mean peak force with cutting speed.

rock plate), $X_{b}$ (height of arc rock plate), $X_{c}$ (thickness of arc rock plate), $X_{d}$ (cutting angle of conical pick), $X_{e}$ (distance of cutting point to arc rock plate central axis), and $X_{f}$ (cutting speed of conical pick).

The statistical software SPSS providing a function of regression analysis was used to carry out multivariate linear regression analysis. The independent variables and the dependent variable needed to be defined before multiple linear regression analysis. The general multivariable regression equation is

$$
Y=\partial+\beta_{1} X_{a}+\beta_{2} X_{b}+\beta_{3} X_{c}+\beta_{4} X_{d}+\beta_{5} X_{e}+\beta_{6} X_{f},
$$

where $Y$ is the dependent variable, $\partial$ is the $Y$-intercept, $\beta_{1}, \beta_{2}$, $\beta_{3}, \beta_{4}, \beta_{5}$, and $\beta_{6}$ are coefficients with $X_{a}, X_{b}, X_{c}, X_{d}, X_{e}$, and $X_{f}$, respectively, and $X_{a}, X_{b}, X_{c}, X_{d}, X_{e}$, and $X_{f}$ are the independent variables' values.

The results of multivariate linear regression analysis need high reliability. The correlation coefficient of the independent, confidence level, significance level, and the $R^{2}$ value are important for the multivariate linear regression analysis.

The results of multivariate linear regression analysis about the sandstone-1 are as follows, including the predictive model about mean peak cutting force of the sandstone- 1 and the predictive model of $F_{m}$ as shown in equation (8):

$$
\begin{aligned}
& F_{m}=-5855.349-0.515 X_{1}-0.404 X_{2}+0.589 X_{3}+0.795 X_{4}+0.267 X_{5}+0.02 X_{6}, \\
& F_{m}=-5855.349-0.515 X_{1}-0.404 X_{2}+0.589 X_{3}+0.795 X_{4}+0.267 X_{5} .
\end{aligned}
$$

Analyzed by SPSS, the confidence level of the analysis is set as 0.95 . The $R^{2}$ value of the predictive model is 0.931 , which is less than 0.05 . The $P$ of the $X_{a}, X_{b}, X_{c}, X_{d}$, and $X_{e}$ is less than 0.05 , and the expression $P \leq 0.05$; therefore, the results of the multivariate linear fitting are reliable. The variation of $F_{m}$ is mainly influenced by the independent variables' width, height, and thickness of arc rock plate, cutting angle, and the distance of cutting point to arc rock plate central axis. However, the cutting speed has less effect on the mean peak cutting force in the process of conical pick cutting arc rock plate. Therefore, the item of cutting speed can be removed to simplify the predictive model, as shown in equation (9).

\section{Conclusion}

The finite element software ANSYS/LS-DYNA was used to research the cracks of arc rock plate forming in the process of conical pick cutting arc rock plate. The numerical simulation (conical pick cutting arc rock plate) with ANSYS/LS-DYNA was established, selecting the JHC constitutive model as the arc rock plate material to simulate the mechanical changes and the arc rock plate cracks forming in the process of conical pick cutting arc rock plate. The number and shape of rock fragments formed were significantly associated with the width, height, thickness, distance of cutting point to arc rock plate central axis, and cutting angle of conical pick.

The results of numerical simulation indicated that the mean peak cutting force is closely connected to the arc rock plate structural parameters and cutting parameters of conical plate. The mean peak cutting force decreases with the width and height increasing. While the width and height of the arc rock plate reach a certain value, the mean peak cutting force tends to a stable value. And the mean peak cutting force increases exponentially with increase of thickness. Distance of cutting point to arc rock plate central 
axis and cutting angle increasing caused the mean peak cutting force decrease and the extent of reduction range decreases. However, the cutting speed has unobvious influence on the mean peak cutting force.

The influence of arc rock plate structural parameters and the cutting parameters on the mean peak cutting force was investigated, and the predictive mathematical model was established. The predictive model indicated that width, height, and thickness of arc rock plate and the distance of cutting point to arc rock plate central axis and the cutting angle influenced the mean peak cutting force greatly. But the cutting speed has unobvious effect on the mean peak cutting force. The thickness of the arc rock plate, cutting angle, and the distance of cutting point to arc rock plate central axis are the positive correction to the mean peak cutting force and the width and height of the arc rock plate are the negative correction with mean peak cutting force.

The cracks of the arc rock plate are influenced greatly by the arc rock plate structural parameters and cutting parameters. Obtained the predictive model by multiple linear regression, it is indicated that the arc rock plate structural parameters have great influence on mean peak cutting force, which can help to guide and optimize the cutting depth in the process of diamond sawblade cutting rock forming arc rock plate. And the predictive model indicated that the distance of cutting point to arc rock plate central axis and the cutting angle have larger influence on the mean peak cutting force. The predictive model can help to determine the appropriate cutting parameters.

\section{Data Availability}

The data used to support the findings of this study are included within the article.

\section{Conflicts of Interest}

The authors declare that there are no conflicts of interest regarding the publication of this paper.

\section{Acknowledgments}

This work was supported by the projects of the National Natural Science Foundation of China (Grant no. 51674155) and the Innovative Team Development Project of the Ministry of Education (Grant no. IRT_16R45).

\section{References}

[1] C. Balci and N. Bilgin, "Correlative study of linear small and full-scale rock cutting tests to select mechanized excavation machines," International Journal of Rock Mechanics and Mining Sciences, vol. 44, no. 3, pp. 468-476, 2007.

[2] R. M. Goktan, "A suggested improvement on Evans' cutting theory for conical bits," in Proceedings of the Fourth Symposium on Mine Mechanization Automation, vol. 1, pp. 57-61, Brisbane, Australia, July 1997.

[3] Y. Nishimatsu, "The mechanics of rock cutting," International Journal of Rock Mechanics and Mining Sciences \& Geomechanics Abstracts, vol. 9, no. 2, pp. 261-270, 1972.
[4] I. Evans, "A theory of the cutting force for point-attack picks," International Journal of Mining Engineering, vol. 2, no. 1, pp. 63-71, 1984.

[5] J. A. H. Hult, "Fatigue crack propagation in torsion," Journal of the Mechanics and Physics of Solids, vol. 6, no. 1, pp. 47-52, 1957.

[6] M. Chrzanowski and J. Hult, "Ductile creep rupture of fibre bundles," Engineering Fracture Mechanics, vol. 28, no. 5-6, pp. 681-688, 1987.

[7] X. Liu, S. Liu, L. Li, and X. Cui, "Experiment on conical pick cutting rock material assisted with front and rear water jet," Advances in Materials Science and Engineering, vol. 2015, no. 1, 9 pages, Article ID 506579, 2015.

[8] D. Che, W. Zhang, and K. Ehmann, "Chip formation and force responses in linear rock cutting: an experimental study," Journal of Manufacturing Science and Engineering, Transactions of the ASME, vol. 139, no. 1, pp. 1-12, Article ID 011011, 2017.

[9] L. J. Yin, Q. M. Gong, H. S. Ma, J. Zhao, and X. B. Zhao, "Use of indentation tests to study the influence of confining stress on rock fragmentation by a TBM cutter," International Journal of Rock Mechanics and Mining Sciences, vol. 72, pp. 261-276, 2014.

[10] J. Huang, Y. Zhang, L. Zhu, and T. Wang, "Numerical simulation of rock cutting in deep mining conditions," International Journal of Rock Mechanics and Mining Sciences, vol. 84, pp. 80-86, 2016.

[11] H. Jiang, C. Du, S. Liu, and Z. Liu, "Numerical analysis of rock cutting based on fracture mechanics," Rock and Soil Mechanics, vol. 34, no. 4, pp. 1179-1184, 2013.

[12] Z. Lu, L. Wan, Q. Zeng, X. Zhang, and K. Gao, "Numerical simulation of fragment separation during rock cutting using a 3D dynamic finite element analysis code," Advances in Materials Science and Engineering, vol. 2017, Article ID 3024918, 17 pages, 2017.

[13] P. Menezes, M. Lovell, I. Avdeev, J. Lin, and C. Higgs III, "Studies on the formation of discontinuous chips during rock cutting using an explicit finite element model," International Journal of Advanced Manufacturing Technology, vol. 70, no. 1-4, pp. 635-648, 2014.

[14] X. Y. Li, Y. G. Lv, S. B. Jiang, and Q. Zeng, "Effects of spiral line for pick arrangement on boom type roadheader cutting load," International Journal of Simulation Modelling, vol. 15, no. 1, pp. 170-180, 2016.

[15] X. Li, B. Huang, G. Ma, and Q. Zeng, "Study on roadheader cutting load at different properties of coal and rock," Scientific World Journal, vol. 2013, Article ID 624512, 8 pages, 2013.

[16] Q. Zeng, Z. Wang, L. Wan, X. Zhang, and Z. Lu, "Study on the damage of coal and rock with diamond saw blade cutting based on ls-dyna," International Journal of Computational Materials Science and Engineering, vol. 6, no. 4, Article ID 1750026, 2018.

[17] H. Jiang, Z. Liu, and K. Gao, "Numerical simulation on rock fragmentation by discontinuous water-jet using coupled SPH/ FEA method," Powder Technology, vol. 312, pp. 248-259, 2017.

[18] J. Tang, Y. Lu, Z. Ge, B. Xia, H. Sun, and P. Du, "A new method of combined rock drilling," International Journal of Mining Science and Technology, vol. 24, no. 1, pp. 1-6, 2014.

[19] Q. Geng, Z. Wei, H. Meng, F. J. Macias, and A. Bruland, "Freeface-assisted rock breaking method based on the multi-stage tunnel boring machine (TBM) cutterhead," Rock Mechanics and Rock Engineering, vol. 49, no. 11, pp. 4459-4472, 2016.

[20] R. Goktan and N. Gunes, "A semi-empirical approach to cutting force prediction for point-attack picks," Journal South 
African Institute of Mining \& Metallurgy, vol. 105, no. 4, pp. 257-263, 2005.

[21] L. Zhu, T. Wei, B. Liu, and T. Yu, "Simulation analysis of rock braking mechanism of tunnel boring machine," Tehnicki Vjesnik, vol. 23, no. 6, pp. 1585-1590, 2016.

[22] S. Liu, H. Ji, X. Liu, and H. Jiang, "Experimental research on wear of conical pick interacting with coal-rock," Engineering Failure Analysis, vol. 74, pp. 172-187, 2017.

[23] J. Rojek, E. Oñate, H. Kargl et al., "Prediction of wear of roadheader picks using numerical simulations," Geomechanics \& Tunnelling, vol. 1, no. 1, pp. 47-54, 2010.

[24] N. Bilgin, M. A. Demircin, H. Copur, C. Balci, H. Tuncdemir, and N. Akcin, "Dominant rock properties affecting the performance of conical picks and the comparison of some experimental and theoretical results," International Journal of Rock Mechanics and Mining Sciences, vol. 43, no. 1, pp. 139-156, 2006. 